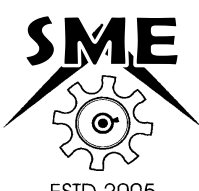

Journal of Manufacturing Engineering, December 2021, Vol. 16, Issue. 4, pp 135-140

\title{
MICROCONTROLLER-BASED VERTICAL FARMING AUTOMATION SYSTEM
}

\author{
*Yuvaraj Kumar S and Santhosh K
}

Department of Agriculture Engineering, Bannari Amman Institute of Technology, Sathyamangalam, Erode, Tamil Nadu-638401, India

\begin{abstract}
Food is an essential need of life. It is how man is fed and reinforced to complete his everyday exercises. The requirement for nourishment for the upkeep of man has set horticulture in charge of man's issues on the planet. With a quickly expanding populace on the planet, man has imagined more up-to-date and inventive ways of developing yields. This development is gathered in country areas of nations all over the planet; yet with the monstrous urbanization occurring in this present reality, it is turning out to be progressively hard to have good horticultural produce that will cook for the gigantic populace. Accepting Nigeria as contextual analysis, the expanded urbanization has put a gigantic expectation ashore, energy and water assets inside the metropolitan region of the country. The larger part of the food eaten in the metropolitan regions is developed in the provincial regions. This framework anyway requires longer transportation times from the provincial areas to metropolitan regions, leading to pollution and deterioration. This examination paper gives an answer in which food harvests can be developed effectively in the metropolitan regions by planting in upward stacked layers to save space and utilize negligible energy and water for water systems.
\end{abstract}

Keywords: Automation; Microcontroller; vertical cultivating.

\section{Introduction}

Cultivating alludes to developing yields or saving creatures by individuals for food and unrefined substances. Cultivating is a piece of horticulture. Corresponding to edit cultivating and domesticated animals cultivating, the expression "agribusiness" might be characterized as the craftsmanship and study of developing plants and different harvests and raising creatures for food, other human requirements, or monetary addition. The cultivating business is a vital area in the world's economies; it is a primary area since cultivating is the sole wellspring of food which remains our main wellspring of energy and imperativeness as people.

It is assessed that constantly 2050 , near $80 \%$ of the total populace will live in metropolitan regions which are exceptionally huge, and the complete populace of the world will increment by 3 billion individuals [1] \& [2]. Furthermore, 70\% expansion in agrarian usefulness will be required. Thus, an exceptionally enormous measure of land might be required to adjust yield per hectare. Researchers are worried that this enormous measure of expected farmland to alleviate this increment won't be accessible and that the additional farmland will cause extreme harm to the earth due to land debasement and loss of soil richness [3-5]. Hence, an increase in crop creation with current innovation (like robotization) to boost the utilization of accessible land is needed [1] \& [6]. Engineers have encouraged that Vertical cultivating is the answer for increment usefulness per region by expanding plant development into the upward aspect, consequently improving area use effectiveness for crop creation [7]. Development of vertical ranch in various layers and compartments is workable for massive scope creation like the one of glasshouse and controlled climate horticulture [8].

Vertical cultivating is the act of delivering food in an upward direction stacked layers. It offers many benefits over ordinary even based cultivating as far as expanded yield creation, preservation of assets, sway on human well-being, metropolitan development, energy maintainability, and so forth. Vertical cultivating may dispense with the need to make extra farmland, assist with establishing a cleaner climate, and address the food emergency in developing urban communities and rural areas.

The advanced thought of vertical cultivating utilizes controlled-climate agribusiness (CEA) innovation [8], where everything ecological elements can be controlled. These offices use fake control of light, ecological control (dampness, temperature, gases),

*Corresponding Author - E-mail: yuvarajkumar.ag19@bitsathy.ac.in 
and fertigation, yet crops are just filled in a fluid arrangement that invalidates its examination with customary even soil establishing framework. Be that as it may, an exploration on vertical soil planting was executed in [1], where plants were filled in the upstanding round and hollow sections and thought about against a traditional level aquaculture framework (HHS). The upward cultivating framework (VFS) created more yields per unit of developing floor region when contrasted and the HHS, however light circulation and shot new weight diminished essentially in the VFS from top to base.

As of late, mechanization is viewed as a fundamental innovation utilized in many fields and activities to control and observe different peculiarities, for example, the water supply, room temperature, voltage vacillation, and so on [9]. Thus, this work means to plan a minimal expense vertical cultivating computerization framework (VFAS) that considers more proficient creation of food by carrying out low voltage sensor innovation to limit wastage of assets and boost returns. By utilizing dampness, light, and temperature sensors, continuous execution of the plant can be recorded, consequently deciding a suitable chance to give water and light to the plants.

As per [10], sickness disease can be observed yields which thus disturbs their creation as far as amount and quality. Consequently, this work observes importance in the way that it works on the amount and nature of harvests become on a little area of land while limiting assets utilized, rather than the conventional strategy for cultivating. This work is set out upon because it is an immediate method for affecting food creation and utilization for those alive, simultaneously producing a reasonable item for the commercial center which would be made reasonable to people. The extent of this work will cover the plan and working of the upward homestead, programming miniature regulator for its computerization, genuine testing with live plants, and execution of the finished work.

\section{Research Materials and Methods}

Clarifying examination ordered, including research configuration, research system (as calculations, Pseudocode or other), how to test, and information securing [1]-[3]. The portrayal of the course of examination ought to be upheld references so that the clarification can be acknowledged deductively [2], [4]. The upward ranch plan contains two particular soil layers with individual lighting, water supply unit, dampness sensor, and temperature sensor in this work.
The plan's front finish highlights solenoid valves that would take care of water through a low voltage water siphon from an overhead water tank. The lighting installations for the ranch would naturally light up or diminish in power because of the degree of lighting in its environs. The rancher can see live information about the plant's exhibition at the back end. The rancher can switch between programmed and manual modes, which would permit him to perform routine support on the homestead, during which he can physically control the water system. The materials used to understand this plan include:

\section{Sensors}

Soil dampness sensor with advanced and straightforward results is set in the dirt and adjusted to take readings. The result from these sensors is utilized to decide the turning on and off of the solenoid valves. The light sensor put on the upward homestead structure screens the light force of the climate and changes the inward lighting to suit the plant's needs. The air temperature sensor gives yield information which is utilized to control the turning ON and OFF of the fans to control the temperature of the homestead.

\section{Water siphon}

The miniature regulator constraints a 12 -volt water siphon in light of simple readings from the dirt dampness sensor. It is utilized to take care of the solenoid valves, which actuate water sprinklers.

\section{Power supply}

The stage voltage of the AC mains to the VAFS is ventured down from $239.6 \mathrm{~V}$ to $15 \mathrm{~V}$ and redressed to $12 \mathrm{~V}$ DC (to drive solenoid valves, water siphon, and fans) and 5V DC (to control miniature regulator and fluid precious stone presentation).

\section{Frameworks Design}

This plan necessitates that the programmed water system framework can consistently detect the dampness level of the dirt. The framework will react suitably by watering the dirt and afterwards shut down the water supply when the necessary degree of dampness is accomplished. The framework plan of this task has different sub-frameworks incorporated together. There are three sub-frameworks. These are power supply sub-framework, detecting sub-framework, and control sub-framework. Figure 1 shows the schematic chart of the undertaking and Figure 2 System's square outline. 


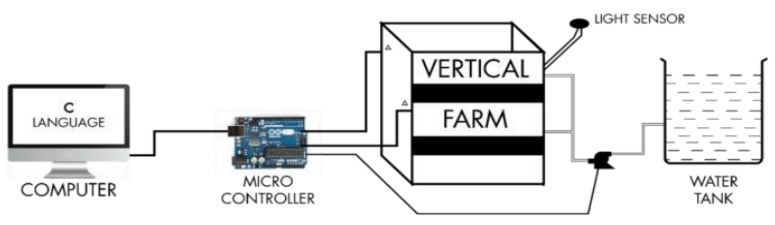

Fig 1. Schematic outline of the venture

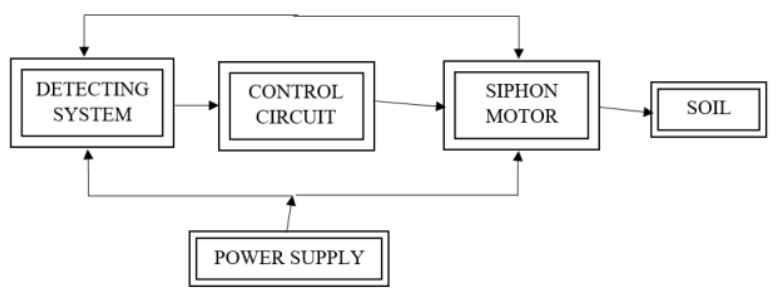

Fig. 2 Framework's square graph

\section{Power supply sub- framework}

The lighting framework (fluorescent light) is controlled from AC mains. The microcontroller, for example, the Arduino Uno, is controlled from a $12 \mathrm{~V}$ DC connector, and the solenoid valves were fueled from a $5 \mathrm{~V}$ DC connector.

\section{Detecting sub- framework}

As mind-boggling as it might appear, the idea of computerisation is a common electronic framework that coordinates a criticism component alluded to as a sensor. The sensor goes about as a marker to sanction an ideal outcome; with sensors, control of any framework is feasible.

For the most part, two sorts of sensors might be utilized to estimate soil water status; those that action soil water potential (additionally called strain or attractions) and those that action volumetric water content straightforwardly. Soil water strain (SWT) addresses the greatness of the pull (negative tension), which the plant attaches need to make to free soil water from the fascination of the dirt, and move it into the root cells. The dryer the dirt, the higher the pull required, subsequently, the higher the SWT. SWT is regularly communicated in centibars or kilopascals.

\section{Soil dampness sensor}

Soil dampness sensors measure the volumetric water content in the soil. Since the direct gravimetric estimation of free soil dampness requires eliminating, drying, and weighting of an example, soil dampness sensors measure the volumetric water content by implication by utilizing another property of the dirt, like electrical obstruction, dielectric steady, or connection with neutrons, as an intermediary for the dampness content. The relationship between the deliberate property and soil dampness should be adjusted and may change contingent upon natural factors, for example, soil type, temperature, or electric conductivity. Reflected microwave radiation is impacted by the dirt dampness and is utilized for remote detecting in hydrology and farming. Ranchers or groundskeepers can thusly utilize versatile test instruments. Figure 3 shows the flash fun soil dampness sensor.

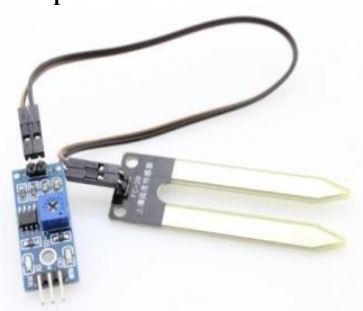

Fig. 3 Flash fun soil dampness sensor

\section{Detecting framework stream graph}

The accompanying stream outline displayed in Figure 4 depicts the essential activity of the dampness detecting framework utilized in this work. To begin with, the dirt dampness sensor estimates the dirt obstruction at stretches sends the data as an advanced sign to the sensor; the microcontroller then chooses whether or not the dirt opposition is high (contingent upon the pre-set edges and soil type). Assuming the dirt dampness level is lower than the pre-set limit, the microcontroller impels the submarine water siphon and solenoid valves, which give water to the dirt employing the trickle water system technique.

\section{Framework Implementation}

The entire robotized vertical cultivating water system framework has both mechanical and electrical parts. The execution of the framework configuration was finished utilizing promptly and locally accessible materials. It this necessary that a few mechanical developments should be completed notwithstanding the advancement of the electronic hardware. Figure 5 shows the $2 \mathrm{D}$ render of the vertical ranch structure.

\section{Mechanical development}

The mechanical developments completed in this plan were those of aluminum works and funneling as displayed in Figure 6.

\section{Electrical hardware}

Execution of the electronic hardware included an actual reenactment of the circuit utilizing a breadboard to guarantee appropriate activity and the last execution of the circuit on a Vero board. Figure 7 shows the detecting and control circuit. 
Journal of Manufacturing Engineering, December 2021, Vol. 16, Issue. 4, pp 135-140

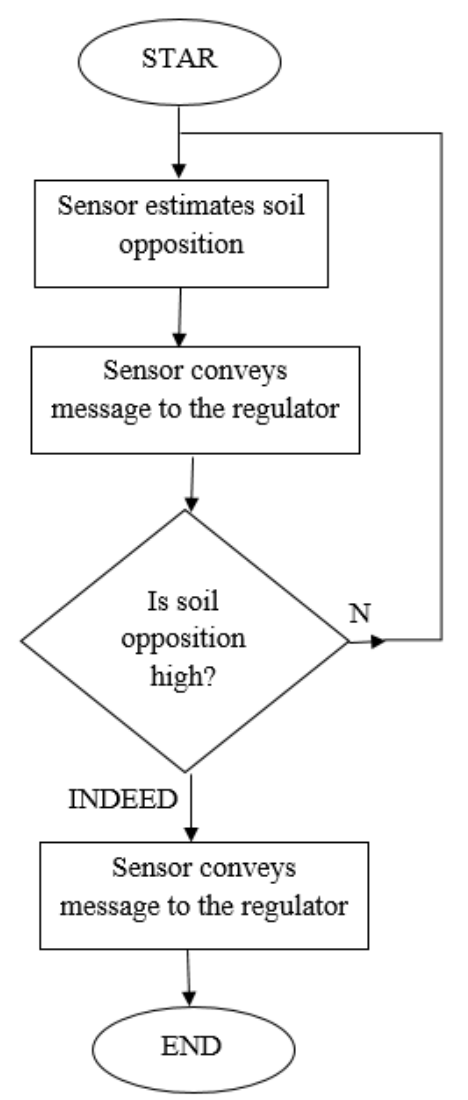

Fig. 4 Flowchart depicting the detecting framework

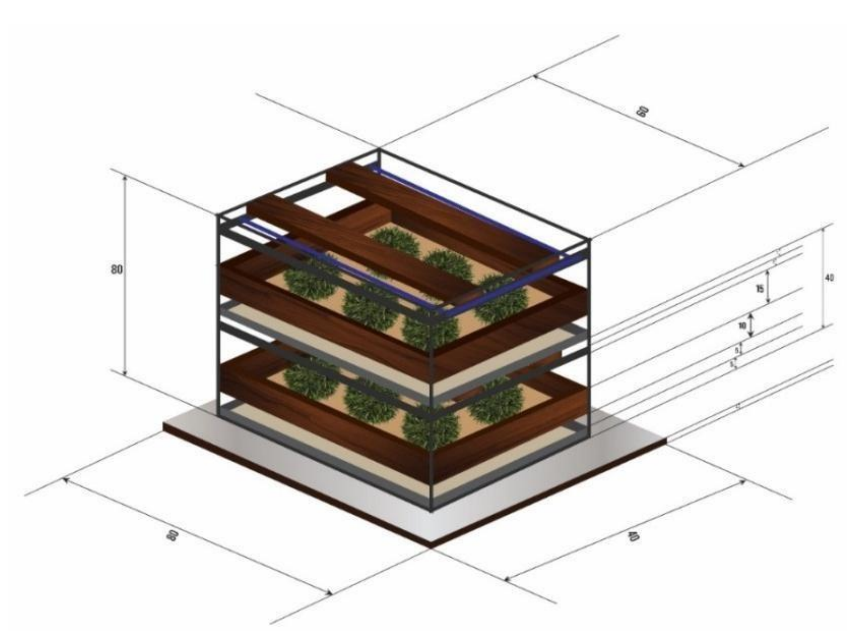

Fig. 5 2D Render of vertical ranch structure

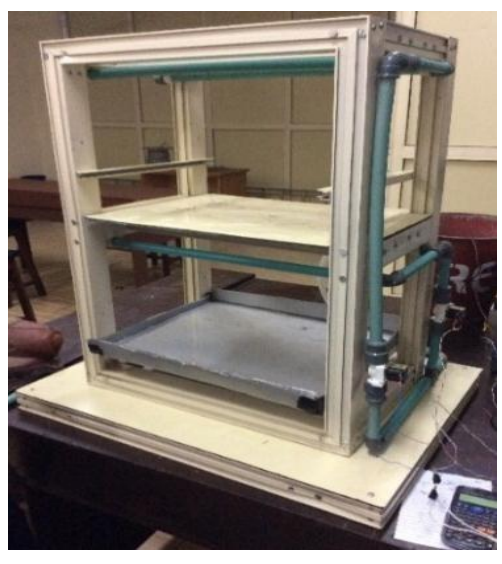

Fig 6. The built aluminum system with channeling

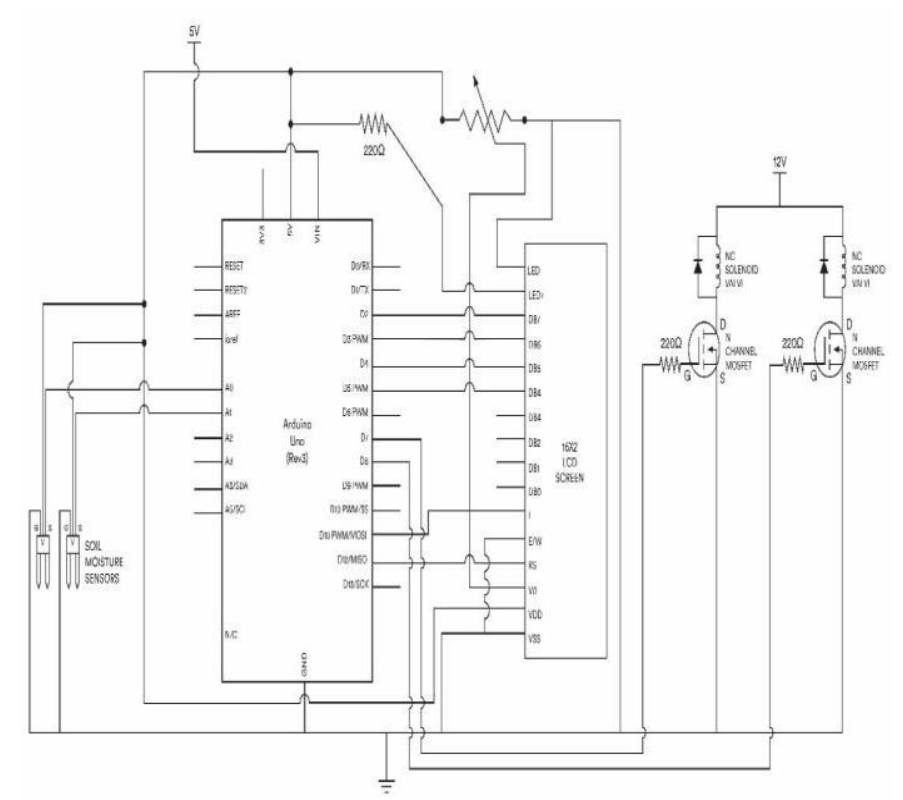

Fig. 7 Detecting and control circuit

\section{Microcontroller programming}

The microcontroller utilized in this task is the Arduino Uno, which has an Arduino coordinated advancement climate (IDE), and it is modified utilizing $\mathrm{C}$ programming language.

The essential elements of the code are laid out underneath:

i. Receive information from simple sensors.

ii. Convert the simple signs to computerized data utilizing an advanced/simple (D/A) converter.

iii. Interpret the computerized data.

iv. Send control signals because of the got computerized data. 


\section{Results and Analysis}

The total framework was tried for the right activity by applying the situation to flood different soil tests. The following is the table of results. Table 1 shows how long the framework took to water different soil tests in various starting states. The information is addressed in the accompanying table:

\begin{tabular}{cccc}
\hline $\begin{array}{c}\text { Soil } \\
\text { sample }\end{array}$ & Soil type & $\begin{array}{c}\text { Starting } \\
\text { soil } \\
\text { state }(\% \\
\text { dryness) }\end{array}$ & $\begin{array}{c}\text { Water } \\
\text { system } \\
\text { time } \\
\text { (seconds) }\end{array}$ \\
\hline A & SANDY & 100 & 6 \\
B & SANDY & 70 & 4 \\
C & SANDY & 50 & 2 \\
D & LOAMY & 100 & 12 \\
E & LOAMY & 70 & 7 \\
F & LOAMY & 50 & 3 \\
G & CLAYEY & 100 & 16 \\
$\mathbf{H}$ & CLAYEY & 70 & 9 \\
I & CLAYEY & 50 & 4 \\
\hline
\end{tabular}

Table 1 Results from Tests Carried out on Various Soil Samples and Soil Types

It tends to be seen from the outcomes acquired in Table 1 that the framework reacted straightly concerning the level of wetness for the three soil types. Figure 8 shows this linearity in a reasonable structure. There is a direct connection between the level of soil dryness and the time taken to inundate the dirt. At half dryness, the water system span was 2.0, 3.0, and 4.0 seconds for sandy, loamy and clayey soil separately. In contrast, at $70 \%$ dryness, the water system length expanded to 4.0, 7.0, and 9.0 seconds for sandy, loamy, and clayey soil individually. It is seen that the water system, by and large, took longer in loamy soil than in sandy soil, and the water system took the longest in clayey soil. Figure 8 shows the dispersed chart of the variety of water system time with soil type.

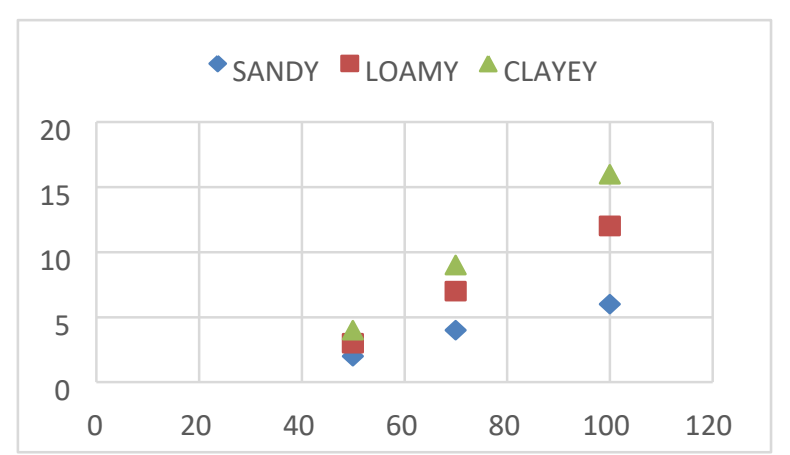

Fig. 8 The dissipate chart of the variety of water system time with soil type

\section{Conclusion}

This work plans and executes a microcontroller-based vertical cultivating mechanization framework. The primary point of the work is to limit the power utilization and water utilization associated with the development of plants. It is a significant commitment when considering the scant accessibility of force and water in the examined space. To accomplish this, a DC water siphon and solenoid valves were sent. These were controlled utilizing the Arduino Uno microcontroller. The microcontroller was modified to enact the solenoid valves to water the plants when the dampness content of the dirt dips under a specific edge. The dirt is flooded until the dirt dampness transcends a pre-set edge, at which the solenoid valves are deactivated. Via computerizing the trickle water system process, water preservation is exhibited because the dirt is watered just when it should be.

Power is rationed in two ways:

i. The detecting and control circuits are immediate current (DC)- controlled, and the control framework is actuated just when information is gotten from the microcontroller.

ii. Energy-saving fluorescents are utilized rather than brilliant lights to lessen how much hotness the lighting framework produces.

The demonstration of planting in upward stacked layers likewise moderates land space. Aside from the way that this work saves energy, water, and land space utilization, it manages cultivating and screen circumstances.

\section{References}

1. Corvalan, Carlos, et al. Ecosystems and human well-being: health synthesis. World Health Organization, 2005.

2. Tilman, David, et al. "Global food demand and the sustainable intensification of agriculture." Proceedings of the national academy of sciences 108.50 (2011): 2026020264.

3. Bonan, Gordon B. "Forests and climate change: forcings, feedbacks, and the climate benefits of forests." science 320.5882 (2008): 1444-1449.

4. Foley, Jonathan A., et al. "Solutions for a cultivated planet." Nature 478.7369 (2011): 337-342.

5. Lambin, Eric F., et al. "Estimating the world's potentially available cropland using a bottom-up approach." Global environmental change 23.5 (2013): 892-901.

6. Lambin, Eric F., and Patrick Meyfroidt. "Global land use change, economic globalization, and the looming land scarcity." Proceedings of the National Academy of Sciences 108.9 (2011): 3465-3472. 
Journal of Manufacturing Engineering, December 2021, Vol. 16, Issue. 4, pp 135-140

7. Eigenbrod, Christine, and Nazim Gruda. "Urban vegetable for food security in cities. A review." Agronomy for Sustainable Development 35.2 (2015): 483-498.

8. Despommier, Dickson. "The vertical farm: controlled environment agriculture carried out in tall buildings would create greater food safety and security for large urban populations." Journal für Verbraucherschutz und Lebensmittelsicherheit 6.2 (2011): 233-236.
9. Alkandari, Abdulrahman Abdullah, and Samer Moein. "Implementation of monitoring system for air quality using raspberry PI: Experimental study." Indonesian Journal of raspberry PI: Experimental study." Indonesian Journal of Electrica

10. Kamal, Mahanijah Md, Ahmad Nor Ikhwan Masazhar, and F. Abdul Rahman. "Classification of leaf disease from image processing technique." Indonesian Journal of Electrical Engineering and Computer Science 10.1 (2018): Electrical 